\title{
Modeled natural and excess radiocarbon: Sensitivities to the gas exchange formulation and ocean transport strength
}

\author{
S. A. Müller, ${ }^{1,2}$ F. Joos, ${ }^{1}$ G.-K. Plattner, ${ }^{1,3}$ N. R. Edwards, ${ }^{4}$ and T. F. Stocker ${ }^{1}$ \\ Received 18 July 2007; revised 19 December 2007; accepted 18 February 2008; published 2 August 2008.
}

[1] Observation-based surface ocean $\Delta^{14} \mathrm{C}$ distributions and regional inventories for excess, bomb-produced radiocarbon are compared with results of two ocean models of intermediate complexity. By applying current descriptions of the air-sea gas exchange the models produce similar column inventories for excess ${ }^{14} \mathrm{C}$ among all basins. This result is robust across a wide range of transport parameter settings, but inconsistent with databased inventories. In the absence of evidence of fundamentally different gas exchange mechanisms in the North Atlantic than in the other basins, we infer regional North Atlantic ${ }^{14} \mathrm{C}$ inventories which are considerably smaller than previous estimates. The results further suggest that the gas exchange velocity field should be reduced by $(19 \pm 16) \%$, which corresponds to a global mean air-sea gas transfer rate for $\mathrm{CO}_{2}$ in seawater of $17.1 \pm 3.3 \mathrm{~cm} \mathrm{~h}^{-1}$, to find good agreement of simulated quantities with a range of data-based metrics.

Citation: Müller, S. A., F. Joos, G.-K. Plattner, N. R. Edwards, and T. F. Stocker (2008), Modeled natural and excess radiocarbon: Sensitivities to the gas exchange formulation and ocean transport strength, Global Biogeochem. Cycles, 22, GB3011, doi:10.1029/2007GB003065.

\section{Introduction}

[2] Knowledge of the spatio-temporal variations of radiocarbon $\left({ }^{14} \mathrm{C}\right)$ in the ocean is needed for many climate science applications such as the reconstruction of solar activity [Muscheler et al., 2005], dating of marine palaeo archives [Ritz et al., 2008], or for quantifying ocean model transport processes [Müller et al., 2006]. The analysis of the cycling of carbon and its isotopes relies on adequate descriptions of the air-sea gas exchange process [e.g., Wanninkhof, 1992; Krakauer et al., 2006] and ocean transport [e.g., Matsumoto et al., 2004]. These processes remain subject to uncertainties, but their timescales can be constrained by ${ }^{14} \mathrm{C}$ observations.

[3] The purpose of this study is to hindcast basin-wide inventories of excess ${ }^{14} \mathrm{C}$ and to infer the air-sea gas transfer velocity. We constrain model results with a range of observation-based metrics such as basin-wide inventories of excess ${ }^{14} \mathrm{C}$ and CFC-11, the global budget of excess ${ }^{14} \mathrm{C}$ and surface ocean natural ${ }^{14} \mathrm{C}$ to ${ }^{12} \mathrm{C}$ ratios $\left(\Delta^{14} \mathrm{C}\right)$. We further examine published basin-wide column inventories of

\footnotetext{
${ }^{1}$ Climate and Environmental Physics, Physics Institute, University of Bern, Bern, Switzerland.

${ }^{2}$ Now at Department of Earth and Environmental Sciences, The Open University, Milton Keynes, UK.

${ }^{3}$ Now at Environmental Physics, Institute of Biogeochemistry and Pollutant Dynamics, ETH Zürich, Zürich, Switzerland.

${ }^{4}$ Department of Earth and Environmental Sciences, The Open University, Milton Keynes, UK.
}

Copyright 2008 by the American Geophysical Union. 0886-6236/08/2007GB003065 excess ${ }^{14} \mathrm{C}$ for their consistency. A suite of multi-millennial simulations is carried out with two computationally efficient, spatially resolved dynamic ocean models.

[4] In order to explore the magnitude of the air-sea gas transfer rate and its functional dependence on external parameters direct measurements of exchange fluxes or deliberate tracer release experiments in the laboratory, rivers, lakes, and the open ocean have been performed [e.g., Liss and Merlivat, 1986; Wanninkhof, 1992; Wanninkhof and McGillis, 1999; Nightingale et al., 2000; Ho et al., 2006]. Different relationships between air-sea gas transfer velocity and wind speed have been proposed, including piecewise linear [Liss and Merlivat, 1986], quadratic [Wanninkhof, 1992; Ho et al., 2006], and cubic [Wanninkhof and McGillis, 1999] formulations. Recently, Krakauer et al. [2006] have utilized the interhemispheric gradient of ${ }^{14} \mathrm{C}$ in the atmosphere, a pulse response substitute model, and other observations to estimate the gas exchange rate and the functional dependence of the air-sea gas exchange on wind speed. They found, in contrast to the results from the SOLAS air-sea gas exchange experiment [Ho et al., 2006], that a near-linear gas transfer-wind speed relationship is best suited to explain their observational constraints. The magnitude of the transfer velocity is usually constrained by excess ${ }^{14} \mathrm{C}$ data [e.g., Broecker et al., 1985; Wanninkhof, 1992]. However, the most recent estimates of the global-mean transfer velocity based on revised inventory estimates for excess ${ }^{14} \mathrm{C}$ [Peacock, 2004; Sweeney et al., 2007] differ by up to about a third [Naegler et al., 2006; Krakauer et al., 2006; Sweeney et al., 2007]. It is of utmost importance that such discrepancies are resolved and the quantitative understanding of the air-sea transfer velocity 
is improved. Uncertainties in the gas transfer velocity are critical for the analysis of carbon isotopes [e.g., Heimann and Maier-Reimer, 1996; Joos and Bruno, 1998] and for determining air-sea carbon fluxes using in situ $\mathrm{CO}_{2}$ partial pressure observations [Takahashi et al., 2002].

[5] Atomic bomb tests in the 1950s and early 1960s added large amounts of ${ }^{14} \mathrm{C}$ to the atmosphere, which almost doubled the atmospheric ${ }^{14} \mathrm{C}$ concentration within a decade. The overall increase of radiocarbon in the reservoirs of the Earth system since the 1950s is usually termed excess ${ }^{14} \mathrm{C}$ or bomb-radiocarbon, here it is defined as the difference to the distribution found directly prior to the atmospheric ${ }^{14} \mathrm{C}$ perturbation [e.g., Siegenthaler, 1989]. Oceanic inventories of excess ${ }^{14} \mathrm{C}$ have been derived from measurements of water samples taken during the GEOSECS global survey in the 1970s, the SAVE and TTO expeditions in the South and North Atlantic in the 1980s, and during the WOCE cruises of the 1990s [Broecker et al., 1985, 1995; Peacock, 2004; Key et al., 2004; Sweeney et al., 2007]. Hesshaimer et al. [1994] concluded that the closure of the Earth system budget of excess ${ }^{14} \mathrm{C}$ appears to be incompatible with estimates of the ocean inventory of Broecker et al. [1985] (which agrees with the estimate of Broecker et al. [1995]). Recently, Naegler and Levin [2006] confirmed this result by showing that the global ${ }^{14} \mathrm{C}$ budget for the second half of the 20th century can be closed by using the revised excess ${ }^{14} \mathrm{C}$ estimates of Peacock [2004].

[6] Excess ${ }^{14} \mathrm{C}$ in the ocean cannot be measured directly, but must be inferred from measurements of total (i.e., natural and excess) radiocarbon utilizing correlations of radiocarbon with other tracers and the few existing prebomb radiocarbon measurements. Different methods have been developed to separate natural and excess radiocarbon [Broecker et al., 1985, 1995; Rubin and Key, 2002; Peacock, 2004; Sweeney et al., 2007] and provide sometimes substantially different estimates of excess radiocarbon even when using the same radiocarbon measurements. Deviations are particularly large in the North Atlantic. Broecker et al. [1995] and Peacock [2004] presented the result that the basin-mean column inventory of excess ${ }^{14} \mathrm{C}$ in the North Atlantic is substantially higher than any other basin-mean column inventory for the GEOSECS and TTO data. However, up to now, the consistency of basin-averaged column inventories between different ocean basins and for currently used air-sea transfer parameterizations has not been tested.

[7] This work adds substantial new information compared to earlier studies [Krakauer et al., 2006; Naegler et al., 2006; Sweeney et al., 2007]. (1) By investigating the consistency among regional, basin-scale inventories of excess ${ }^{14} \mathrm{C}$ simulated with a commonly used air-sea gas transfer velocity parameterization, we are able to identify a discrepancy between the observation-based, basin-averaged column inventories of excess ${ }^{14} \mathrm{C}$ in the North Atlantic with the inventories of other basins. (2) Using a novel suite of data-based metrics, we provide a new estimate of the air-sea gas transfer velocity. In addition, the modeling approach presented here has novel aspects and several advantages compared to other studies. First, the application of two cost-efficient models allows carrying out over a hundred millennial-scale simulations, which would be prohibitively costly with state-of-the-art ocean general circulation models. On the other hand, the two models feature important aspects of ocean dynamics not captured by simple box models. We have systematically varied the gas transfer climatology used in phase two of the Ocean Carbon Cycle Model Intercomparison Project (OCMIP-2) [Orr, 1999] in forward simulations with both models. The diapycnal diffusivity constant $\left(K_{d}\right)$, a parameter governing ocean transport, has also been varied over a wide range in the Bern3D model. In total, the models have been run for around two million model years. Second, we simulate both the cycling of natural and of bomb-produced radiocarbon. This is in contrast to previous studies [e.g., Sweeney et al., 2007] that considered the bomb perturbation only. The dilution of the atmospheric ${ }^{14} \mathrm{C}$ signal by the burning of radiocarbon-free fossil fuel is explicitly taken into account as is the rise in atmospheric $\mathrm{CO}_{2}$ over the industrial period. Third, the airsea gas transfer velocity has-been tuned to match basin-wide ${ }^{14} \mathrm{C}$ inventories, not individual ${ }^{14} \mathrm{C}$ profiles. Potential biases and uncertainties arising from uncertainties in ocean transport are very small for simulated basin-wide inventories, but may be substantial for individual profiles. Finally, we rely on a multitracer approach to constrain air-sea gas transfer and ocean transport. Müller et al. [2006] tuned the Bern3D model to match a number of CFC-11 and deep-ocean natural radiocarbon constraints as suggested by Matsumoto et al. [2004] and evaluated it by comparing simulated and data-based profiles for a number of transient tracers. Here, we explicitly utilize data-based estimates of basin-wide CFC-11 inventories to estimate the range of permissible ocean transport parameters.

\section{Methods}

\subsection{Bern3D Model}

[8] The physical core of the Bern3D model is the frictional geostrophic ocean model described by Müller et al. [2006], which is based on the ocean model of Edwards et al. [1998]. Model resolution is the same as used by Müller et al. [2006]. Transport parameters have been tuned to match data-based inventories of CFC-11 and deep ocean $\Delta^{14} \mathrm{C}$ signatures and the comparison between simulated and observed distributions of anthropogenic carbon, natural and excess radiocarbon, $\mathrm{CFC}-11$ and ${ }^{39} \mathrm{Ar} / \mathrm{Ar}$ suggest that surface-to-deep transport rates are simulated realistically [Müller et al., 2006]. As by Müller et al. [2006], sea surface temperatures and salinities are restored toward climatological values. Then, seasonally varying salinity flux fields are diagnosed to provide the salinity flux boundary conditions for the mixed boundary conditions (MBC) scheme used in the subsequent experiments. Wind stress fields are from a linear interpolation of NCEP reanalysis [Kalnay et al., 1996] derived momentum flux data, provided by the NOAA-CIRES Climate Diagnostics Center, Boulder, Colorado, USA from their Web site at http://www.cdc.noaa.gov/. Exchange through the Strait of Gibraltar is diffusive only. The additional convection algorithm which precedes the conventional convection described by Müller et al. [2006] was turned off for passive tracer in the three grid-boxes representing deep water production in the Ross and Weddell 
Seas to reduce spurious tracer uptake. This modification does not affect our main conclusions.

[9] CFC-11, dissolved inorganic carbon (DIC), ${ }^{14} \mathrm{C}$ and gas-exchange are implemented following the protocols of the OCMIP-2 [Orr, 1999] (additional details on the ${ }^{14} \mathrm{C}$ implementation can be found in the Appendix), the carbonate chemistry determining $\mathrm{pCO}_{2}$ in the surface ocean is solved using the algorithms as updated for OCMIP-3 (http:// www.ipsl.jussieu.fr/OCMIP/). In a sensitivity run, the marine biological and calcite cycles are considered, and DIC and DIC14 as well as phosphate and alkalinity are modeled as in the OCMIP-2. In the standard setup the marine biological cycle has a small impact on simulated global inventories of excess ${ }^{14} \mathrm{C}(<2 \%$ until 1992) and is thus ignored. The model uses the rigid lid approximation and, contrary to the OCMIP-2 protocols, all tracers are transported salinity-normalized and no virtual fluxes for carbon are applied.

[10] The model is run for $15 \mathrm{ka}$ to determine quasi steady state solutions for DIC and radiocarbon. Atmospheric $\mathrm{CO}_{2}$ and $\Delta^{14} \mathrm{C}$ are kept constant at $278.0 \mathrm{ppm}$ and $0 \%$ until $1770 \mathrm{AD}$ when the transient simulations are started and atmospheric CFC-11 concentrations and $\Delta^{14} \mathrm{C}$ are prescribed from data-based estimates according to the protocols of the OCMIP-2. Atmospheric $\mathrm{CO}_{2}$ is prescribed from the smoothing spline fit through ice core data and atmospheric measurements used by Müller et al. [2006].

\subsection{Bern2.5D Model}

[11] The Bern2.5D reduced complexity climate model includes components describing the physical climate system, the cycling of carbon and related elements, and a module to calculate radiative forcing by atmospheric $\mathrm{CO}_{2}$, non- $\mathrm{CO}_{2}$ greenhouse gases and aerosols designed to investigate the effect of climate change on modeled tracer fields. The physical component is the zonally averaged, 3-basin ocean circulation model, coupled to a zonally and vertically averaged atmospheric energy balance model, of Stocker et al. [1992]. The physical model setup and parameters are as applied by Plattner et al. [2001]. The ocean carbon cycle component is the standardized description of the abiotic cycles of DIC and radiocarbon of the OCMIP-2 [Orr, 1999]. The model is spun up over a total of $19 \mathrm{ka}$.

[12] Atmospheric $\mathrm{CO}_{2}$ and $\Delta^{14} \mathrm{C}$ histories are prescribed according to the OCMIP-2 abiotic protocol. The sensitivity of excess ${ }^{14} \mathrm{C}$ inventories to $\mathrm{CO}_{2}$-induced climate change is investigated in runs where the additional $\mathrm{CO}_{2}$ affects the radiative balance at the top of the atmosphere. Global oceanic inventories of excess ${ }^{14} \mathrm{C}$ are slightly reduced (by less than $2 \%$ ) in simulations with climate change compared to simulations without climate change. Results from runs excluding climate change are presented hereafter.

\subsection{Examined Sensitivities and Standard Model Setup}

[13] The OCMIP-2 gas transfer velocity field was varied by adjusting an overall scaling factor $\beta$ over a range from 0 to 2 in steps of 0.1 in both models. This procedure retains the spatial pattern of the field but adjusts the global mean gas exchange rate. Further, the use of the commonly used gas transfer velocity field from the OCMIP-2 in both models allows its examination and the comparison of results simulated with different representations of ocean physics, which have been described previously. Additionally, in the Bern3D model, the gas exchange field $\left(k_{l, 2}\right)$, originally proportional to the wind speed squared relationship from Wanninkhof [1992], has been varied to mimic the proportionality of the gas exchange rate to wind speed to different powers $u^{n}$, where $u=\sqrt{k_{l, 2}}$ is an approximation of the wind speed and $n$ has been set to $0,1,2$, or 3 , respectively (equation (A5) in the Appendix).

[14] The Bern3D model features a rather weak Meridional Overturning Circulation (MOC) in the Atlantic of around $14 \mathrm{~Sv}$ and relatively weak equatorial upwelling in the Pacific (about $4 \mathrm{~Sv}$ ) [Müller et al., 2006] whereas in the Bern2.5D model the Atlantic MOC reaches about $24 \mathrm{~Sv}$ with strong equatorial upwelling in the Pacific [Marchal et al., 1998]. The Bern3D model's Antarctic Circumpolar Current is too weak (around $48 \mathrm{~Sv}$ ) [Müller et al., 2006] (the Bern2.5D model is zonally well-mixed in the Southern Ocean by design). The two models bracket, in their standard setup, data-based estimates for the Atlantic MOC strength [Ganachaud and Wunsch, 2000; Talley et al., 2003]. Additionally, in the Bern3D model $K_{d}$ was varied between 0.5 and $20 \times 10^{-5} \mathrm{~m}^{2} \mathrm{~s}^{-1}$ to explore a large range of different surface-to-deep mixing rates and of the model's advective transport strength. The resulting maximum North Atlantic MOC strengths range approximately from $13 \mathrm{~Sv}$ to $27 \mathrm{~Sv}$, well exceeding the data-based range for NADW production of $15 \pm 2 \mathrm{~Sv}$ of Ganachaud and Wunsch [2000] and around $18 \mathrm{~Sv}$ of Talley et al. [2003]. Correspondingly, the MOC in the Pacific is of opposite sign and varies from -12 to $-32 \mathrm{~Sv}$.

\section{Data-Based Reconstructions of Inventories of Excess ${ }^{14} \mathrm{C}$ and Pre-perturbation Surface Ocean $\Delta{ }^{14} \mathrm{C}$}

[15] Oceanic inventories of bomb-produced radiocarbon have been estimated by Broecker et al. [1985, 1995], Peacock [2004], Key et al. [2004], and Sweeney et al. [2007]. Radiocarbon measurements include both the natural (background) and the excess contribution which have to be separated. Broecker et al. [1985] estimated the excess radiocarbon component using pre-perturbation estimates of surface $\Delta^{14} \mathrm{C}$ and assumed that the depth profile of excess radiocarbon is similar to that of tritium. Later, Broecker et al. [1995] applied the observed correlation between silica and natural $\Delta^{14} \mathrm{C}$ in waters assumed to be free of excess ${ }^{14} \mathrm{C}$ to estimate the natural radiocarbon contribution. More recently, Rubin and Key [2002] and Key et al. [2004] utilized a functional relationship between potential alkalinity and natural radiocarbon to estimate the background component for the GEOSECS and the GLODAP data. This method was modified by Sweeney et al. [2007] by relating natural $\Delta^{14} \mathrm{C}$ to both potential alkalinity and apparent oxygen utilization. Mostly, the different methods give similar results. However, they differ noticeably in some regions [e.g., Rubin and Key, 2002]. For example, for GEOSECS data north of $28^{\circ} \mathrm{N}$ in the Atlantic, column inventories of excess ${ }^{14} \mathrm{C}$ estimated by Broecker et al. 
(a) Western Atlantic

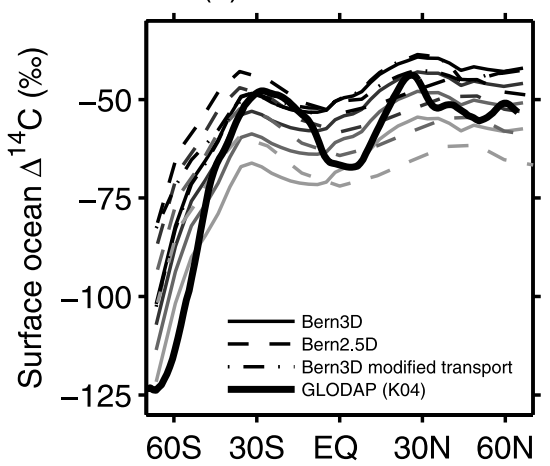

(c) Western Pacific

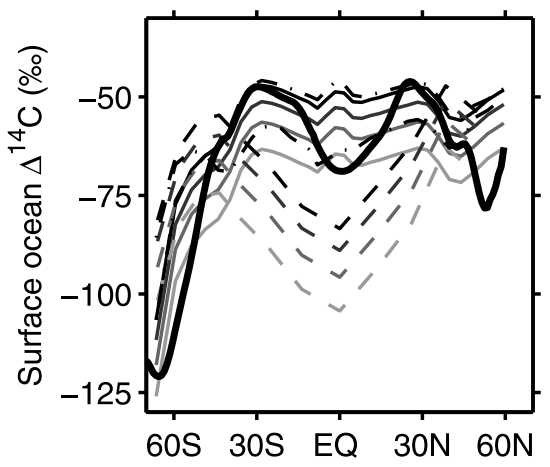

(b) Eastern Atlantic

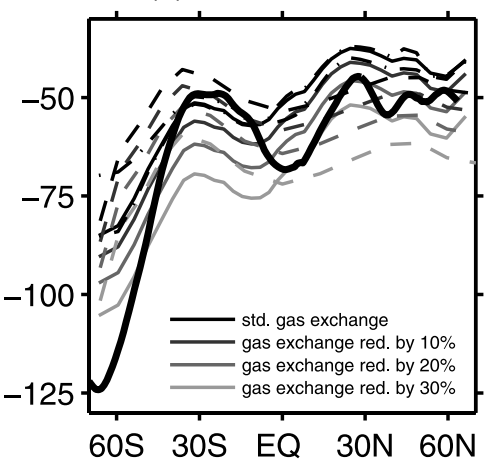

(d) Eastern Pacific

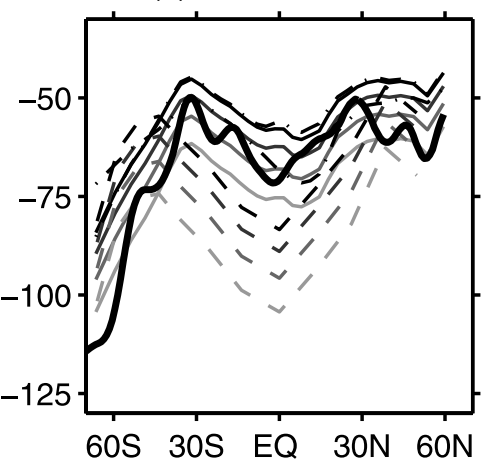

Figure 1. Zonally averaged pre-perturbation $\Delta^{14} \mathrm{C}$ distributions in the surface ocean simulated with the Bern3D (thin solid) and Bern2.5D (dashed) models. The bold lines indicate zonally averaged reconstructions for natural $\Delta^{14} \mathrm{C}$ of Key et al. [2004] (K04). Model simulations are performed with the standard (black) and reduced gas exchange velocity of $90 \%$ (dark gray), 80\% (gray), and 70\% (light gray) of the original strength, and with reduced and increased mixing and transport strengths (Bern3D model only, dash-dotted curves) by applying $K_{d}$ of $5 \times 10^{-6} \mathrm{~m}^{2} \mathrm{~s}^{-1}$ and of $5 \times 10^{-5} \mathrm{~m}^{2} \mathrm{~s}^{-1}$. The separation between western (left) and eastern (right) sections is along $20^{\circ} \mathrm{W}$ in the Atlantic and along $160^{\circ} \mathrm{W}$ in the Pacific.

[1995] exceed those estimated by Rubin and Key [2002] (where available by up to about $50 \%$ ) and Broecker et al. [1985] (by up to about 75\%).

[16] Column inventories must be extrapolated from the few observations to entire basins in order to obtain inventories of excess ${ }^{14} \mathrm{C}$. Broecker et al. [1995] binned column inventories in $10^{\circ}$ latitude bands and scaled them with the ocean surface area of the latitude band. Peacock [2004] applied a model-derived correction factor from uptake patterns of simulated CFC-11 and anthropogenic DIC for off-shelf regions to the inventory estimates of Broecker et al. [1995] in order to extrapolate the scarce GEOSECS radiocarbon data over latitudinal bands. Using this method Peacock [2004] estimates the global ocean bomb-produced radiocarbon inventory ti lie between 268 and $274 \times 10^{26}$ atoms (adjusted for 1975), significantly lower than the estimate of $305 \times 10^{26}$ atoms by Broecker et al. [1995] for 1975. To account for areas of shallow waters, Broecker et al. [1995] and Peacock [2004] applied a correction of $26 \times 10^{26}$ atoms. Peacock [2004] also presented a multitracer regression to extrapolate the sparse measurements of total radiocarbon before their separation. This leads to an inventory estimate between 224 and $258 \times 10^{26}$ atoms.
[17] The GLODAP data set provides a dense set of direct radiocarbon measurements and estimates of the natural and excess components. However, when the data set was created, most samples of the WOCE era from the Atlantic were not analyzed. Instead, the data set was complemented with data from earlier measurements taken in the 1980s [Key et al., 2004], which leads to uncertainties in the integration of the global and especially the North Atlantic inventory. Recently, Sweeney et al. [2007] applied a model ensemble in an inversion study to interpolate measurements from the 1970s to the 1990s and present the temporal evolution of the global, but not basin-wide, excess radiocarbon inventory.

[18] Differences between the models' basin surface areas and the areas used in the data-based reconstructions are generally small. The biggest differences are less than $4 \%$ for the Bern3D model. The Bern2.5D model's surface area is $9 \%$ too large in the South Atlantic and 14\% too small in the North Atlantic (Note, that there is no Arctic Ocean basin represented in the Bern2.5D model, only a small fraction of the Atlantic extends north of $70^{\circ} \mathrm{N}$ ). However, the missing Arctic in the Bern2.5D model would in large parts be covered by ice and thus this error only partially affects 
(a) Western Atlantic

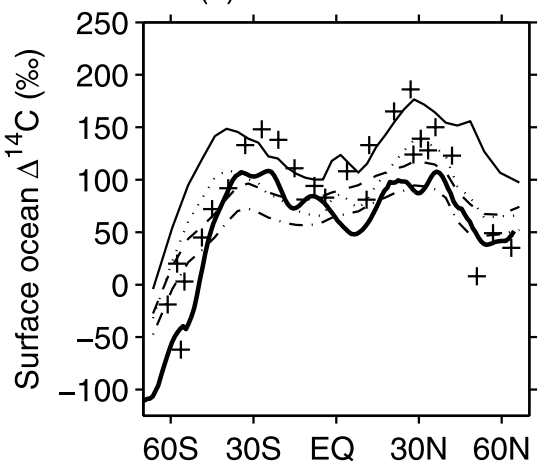

(c) Western Pacific

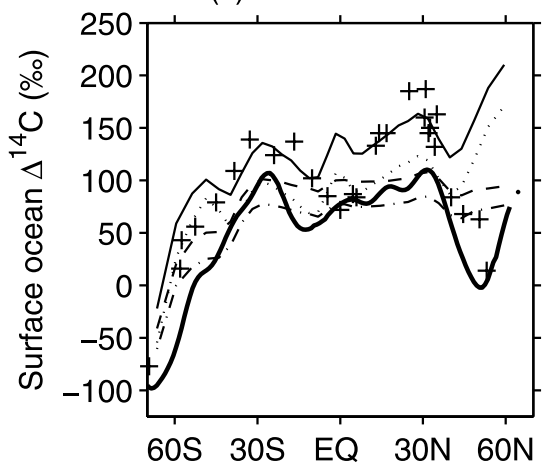

(b) Eastern Atlantic

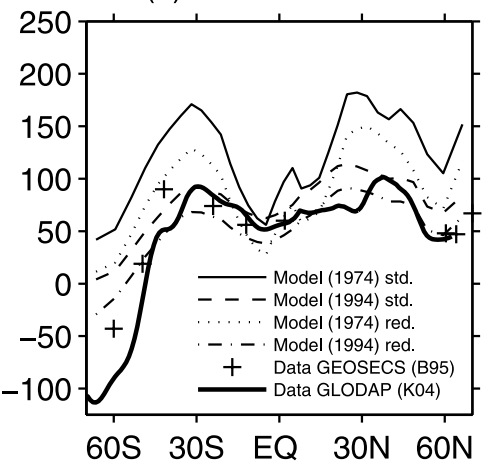

(d) Eastern Pacific

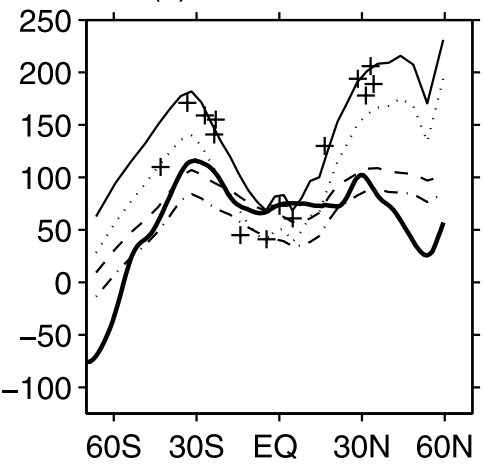

Figure 2. $\Delta^{14} \mathrm{C}$ in the surface ocean for the GEOSECS (1974, solid) and WOCE era (1994, dashed) as simulated with the Bern3D model. Results with the gas exchange rate reduced by $20 \%$ for the GEOSECS (dotted) and the WOCE (dash-dotted) eras are shown. Symbols denote the GEOSECS values reported by Broecker et al. [1995] (B95). The bold lines indicate zonally averaged reconstructions for total $\Delta^{14} \mathrm{C}$ of Key et al. [2004] (K04). The separation between western (left) and eastern (right) sections is as in Figure 1.

the area over which air-sea gas-exchange occurs. No attempt has been made to correct the simulated inventories for these differences when they have been compared with the corresponding data-based estimates.

\section{Natural $\Delta^{14} \mathrm{C}$ Distribution and the Increase in Surface Ocean $\Delta^{14} \mathrm{C}$}

[19] The Bern3D model simulates the large scale features of the deep ocean natural $\Delta^{14} \mathrm{C}$ distribution reasonably well [Müller et al., 2006]. The standard simulations of the Bern3D and Bern2.5D model, i.e., using the standard gasexchange formulation $(\beta=1)$ in both models and the standard transport parameter in the Bern3D model, coarsely agree with the gridded GLODAP data set [Key et al., 2004] (Figure 1). The simulated surface ocean distribution of preperturbation $\Delta^{14} \mathrm{C}$ exhibits the disequilibria in $\Delta^{14} \mathrm{C}$ caused by the interplay of air-sea gas exchange, oceanic transport, and radioactive decay.

[20] The $\Delta^{14} \mathrm{C}$ gradient seen in the data between the Equator and the midlatitudes is basically absent in the simulations of the Atlantic distribution. The Bern2.5D simulation substantially underestimates the magnitude of the equatorial values in the Pacific basin, which is in contrast to the weak gradient between the midlatitudes and the Equator simulated with the Bern3D model. This is probably due to the high Pacific equatorial upwelling strength found in the simulation of the Bern2.5D model [Marchal et al., 1998], which is much lower in the Bern3D model [Müller et al., 2006]. The simulated values mostly exceed the data-based GLODAP reconstruction of natural $\Delta^{14} \mathrm{C}$ in both the Atlantic and Pacific basins. However, the data-based values are largely covered for simulations with a gas-exchange rate reduced by $0 \%$ to $30 \%$. Sensitivity analyses show that increased surface-to-deep mixing and transport rates affect the distribution substantially in the Pacific, while in the Atlantic upwelling of old water masses is less prevalent, and thus changes in transport affect the distribution much less strongly than in the Pacific. The simulated Southern Ocean and high-latitude North Pacific $\Delta^{14} \mathrm{C}$ values are noticeably higher than the data-based values suggest.

[21] The rise in simulated surface $\Delta^{14} \mathrm{C}$ values from the beginning of the bomb tests to the time of the GEOSECS cruises broadly agrees with observations in the Atlantic and Pacific [Broecker et al., 1995] (Figure 2 shows results from Bern3D simulations). The invasion of bomb-produced radiocarbon causes $\Delta^{14} \mathrm{C}$ to rise in the surface ocean by around 200. In agreement with observations, the model simulates relatively low $\Delta^{14} \mathrm{C}$ values in the equatorial Atlantic and Pacific and high values in the subtropical gyres in the early seventies. The $\Delta^{14} \mathrm{C}$ values simulated with the 
Bern3D model in the Southern Ocean are higher than the data-based values for the GEOSECS era, indicating that radiocarbon uptake could be too vigorous in the Southern Ocean. Simulated values are also higher than the data points in the subpolar region of the North Pacific suggest. The too weak formation of NADW in the standard simulation with the Bern3D model is reflected by too-high surface values around $60^{\circ} \mathrm{N}$. In conclusion, the models simulate the large scale features of the surface $\Delta^{14} \mathrm{C}$ distribution as well as the temporal evolution of surface $\Delta^{14} \mathrm{C}$, while showing deficiencies in some regions.

\section{Controls on the Oceanic Uptake of Excess ${ }^{14} \mathrm{C}$ on a Basin Scale}

[22] The equilibration time of the surface ocean $\Delta^{14} \mathrm{C}$ to an atmospheric perturbation is of the order of a decade. The change in surface ocean $\Delta^{14} \mathrm{C}$ is small compared to the atmospheric changes at least until the GEOSECS cruises in the 1970s. The relative importance of transport processes removing excess ${ }^{14} \mathrm{C}$ from the surface ocean is thus small, and uncertainties related to oceanic transport can be expected to have a small impact on the estimate of uptake of excess ${ }^{14} \mathrm{C}$ and large-scale inventories.

[23] The simulated uptake of excess ${ }^{14} \mathrm{C}$ compared with the potential uptake of an ocean with an infinitely fast surface-to-deep transport (i.e., the surface ocean does not react to the perturbation and remains fixed at its preperturbation value) can be approximated using

$$
f_{u}(t) \approx \frac{\int_{t_{0}}^{t} \mathrm{~d} t^{\prime}\left(\Delta \Delta^{14} \mathrm{C}_{\mathrm{a}}\left(t^{\prime}\right)-\Delta \Delta^{14} \mathrm{C}_{\mathrm{s}}\left(t^{\prime}\right)\right)}{\int_{t_{0}}^{t} \mathrm{~d} t^{\prime} \Delta \Delta^{14} \mathrm{C}_{\mathrm{a}}\left(t^{\prime}\right)},
$$

where $\Delta \Delta^{14} \mathrm{C}_{\mathrm{a}}$ denotes the deviation in atmospheric $\Delta^{14} \mathrm{C}$ from the value at the beginning of 1954. In equation (1) the change in atmospheric $\mathrm{pCO}_{2}$ and variations in atmospheric pressure have been neglected, and the surface ocean is considered to be in equilibrium with atmospheric $\mathrm{pCO}_{2}$. The surface ocean deviation, $\Delta \Delta^{14} \mathrm{C}_{\mathrm{s}}$, is calculated from the standard Bern3D simulation. The resulting fraction, $f_{u}(t)$, is between $72 \%$ and $80 \%$ between 1971 and 1979 , the time of the GEOSECS cruises. Although surface ocean $\Delta^{14} \mathrm{C}$ approaches the atmospheric $\Delta^{14} \mathrm{C}$ and surface-todeep transport becomes more important in determining the actual uptake, the fractional uptake decreases only to about $60 \%$ in the mid-1990s, the time of the WOCE cruises. Thus ocean transport only plays an inferior role compared to air-sea gas exchange for basin to global scale inventories of excess ${ }^{14} \mathrm{C}$.

[24] Exchange fluxes of excess ${ }^{14} \mathrm{C}$ among basins are small for large basins compared to the uptake through the air-sea interface. Transport across the equatorial Atlantic Ocean might influence the basin-scale results, as excess- ${ }^{14} \mathrm{C}$ rich surface water enters the North Atlantic, while the southward transported water in the deep ocean is still hardly influenced by excess ${ }^{14} \mathrm{C}$. The effect of this pathway is small compared to the inventories of excess ${ }^{14} \mathrm{C}$ [Broecker et al., 1995]. Net transport across the equator in the Atlantic is estimated around $3 \times 10^{26}$ atoms in the Bern3D model (with $K_{d}$ set to the standard value) until 1975 (around $9.5 \times$
$10^{26}$ atoms for 1994), smaller than the estimate of Broecker et al. [1995] of $8 \times 10^{26}$ atoms. By 1975, net transport across the zonal boundaries into the South Atlantic sector is estimated about $3 \times 10^{26}$ atoms higher from the South Pacific sector than what is lost into the South Indian Ocean. Also a net loss from the Indian Ocean into the Pacific of around $2 \times$ $10^{26}$ atoms is simulated. While the exact magnitude of these net fluxes are model specific, they are of minor importance in the simulation of basin-wide inventories of excess ${ }^{14} \mathrm{C}$.

[25] The spatio-temporal pattern of the gas transfer velocity depends on the parameterization with respect to the wind speed, $u^{n}$. In all basins, the simulated basin-averaged column inventory depends only weakly on the assumed parameterization (Figure 3), and the standard wind speed squared relation provides an intermediate value for all inventories.

[26] In conclusion, simulated basin-averaged inventories of excess ${ }^{14} \mathrm{C}$ are approximately equal to the cumulated basin-averaged uptake through the air-sea interface and roughly proportional to the magnitude of the averaged airsea gas transfer velocity.

\section{Sensitivity of Excess ${ }^{14} \mathrm{C}$ Inventories to the Global Mean Gas Exchange Rate and Ocean Transport}

[27] The magnitude of the gas transfer velocity and ocean transport is varied systematically, similar to the box model simulation for the global ocean excess ${ }^{14} \mathrm{C}$ inventory and surface $\Delta^{14} \mathrm{C}$ by [Broecker et al., 1986], as described in subsection 2.3 , to quantify the sensitivity of excess ${ }^{14} \mathrm{C}$ uptake in both models. The goal is to constrain the magnitude of the air-sea gas transfer velocity for a realistic range of surface-to-deep transport. Results of these simulations are displayed in Figures 4 and 5 for the Bern3D model.

[28] Table 1 displays inventories of excess ${ }^{14} \mathrm{C}$ simulated with both models as well as data-based estimates for the global ocean and various basins and cruises [Broecker et al., 1995; Peacock, 2004; Key et al., 2004]. The global inventory of Broecker et al. [1995] of $305 \times 10^{26}$ atoms is matched within $0.7 \%$ by both models. This is to be expected since the OCMIP-2 gas exchange field has been scaled to the Broecker et al. [1985] inventory estimate for the GEOSECS era, which itself is in close agreement with the estimate of Broecker et al. [1995], and because the global inventory does only weakly depend on ocean transport. However, the modeled inventories are considerably higher than the revised inventories of Peacock [2004] for the global ocean, the Pacific for the WOCE era (1990s), and the South Atlantic for the SAVE cruises (1987-1989). The modeled Pacific and Indian Ocean inventories for the GEOSECS era (1973/74, 1977/78, respectively) are slightly higher than the revised inventory of Peacock [2004]. In contrast, the simulated inventory for the North Atlantic is substantially lower than the data-based estimates from Broecker et al. [1995] (by up to 48\%) and Peacock [2004] (by up to $30 \%$ ).

[29] A further estimate of the global oceanic excess ${ }^{14} \mathrm{C}$ inventory can be found by closing the Earth system budget of excess ${ }^{14} \mathrm{C}$. This is especially simplified after 1963, when atmospheric bomb tests became relatively rare and the global 

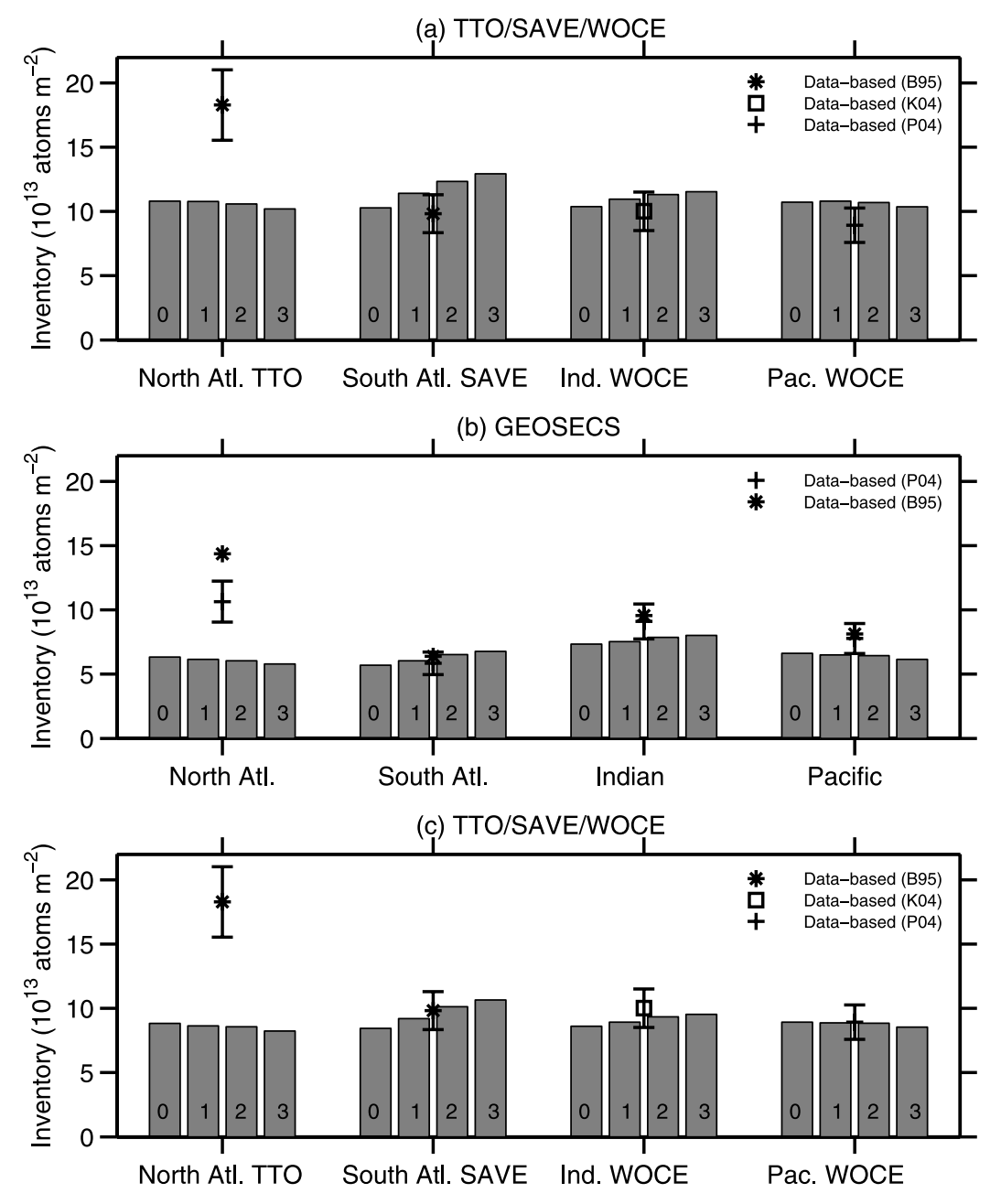

Figure 3. Basin-wide column inventories of excess ${ }^{14} \mathrm{C}$ for different gas exchange-wind speed relationships. Numbers in bars denote the exponent in the applied $u^{n}$ gas exchange-wind speed relation. Model results are shown for the Bern3D model and the standard gas exchange velocity field of the OCMIP-2 was used (a) without scaling and (b, c) downscaled by 19\%. Data-based estimates of Broecker et al. [1995] (B95, stars), Peacock [2004] (P04, plus signs), and integrated from the GLODAP data set [Key et al., 2004] for the Indian Ocean (K04, square) are shown. The error bars indicate an assumed uncertainty of $\pm 15 \%$. Note, that the modeled inventories shown in Panels $\mathrm{b}$ and $\mathrm{c}$ have been adjusted to remove the contribution due to changes in DIC (Table 1), while modeled inventories in Panel a have not been modified.

budget remained approximately constant. Observations and models permit the quantification of the change of artificially produced ${ }^{14} \mathrm{C}$ in the stratosphere, troposphere, and biosphere, and the total artificial production of ${ }^{14} \mathrm{C}$ can be estimated from statistics. The net-balance, excluding the ocean, is estimated to be $-228 \pm 50 \times 10^{26}$ atoms by Joos [1994] and to lie between -240 and $-265 \times 10^{26}$ atoms based on the results of Naegler and Levin [2006] (T. Naegler, personal communication, 2007) for the period from July 1965 to July 1989 , which implies a corresponding oceanic uptake. The simulated change is $291 \times 10^{26}$ atoms for the standard setup in the Bern3D model and even higher in the Bern2.5D model (Table 1).

[30] Diagnosed inventories of excess ${ }^{14} \mathrm{C}$ are based on measurements of $\Delta^{14} \mathrm{C} .{ }^{14} \mathrm{C}$ inventories are, in addition to the atmospheric $\Delta^{14} \mathrm{C}$ perturbation, also influenced by increasing DIC concentrations. Generally, the data-based estimates used for this study have been estimated under the assumption of constant oceanic DIC concentrations and thus underestimate the actual inventories by a few \% (T. Naegler, Reconciliation of excess ${ }^{14} \mathrm{C}$-constrained global $\mathrm{CO}_{2}$ piston velocity estimates, submitted to Tellus. Series B, 2008). Table 1 reports the influence of changing DIC concentrations on the inventory estimates. In summary, the comparison of the standard simulations with the range of data-based reconstructions considered here suggests that the gas transfer velocities from the OCMIP-2 are too high. A notable exception is the inventory of excess ${ }^{14} \mathrm{C}$ of the North Atlantic which is substantially underestimated by the two models compared to published estimates.

[31] The data-based inventories of CFC-11 in the Pacific and Indian Ocean of Willey et al. [2004] and inventories 

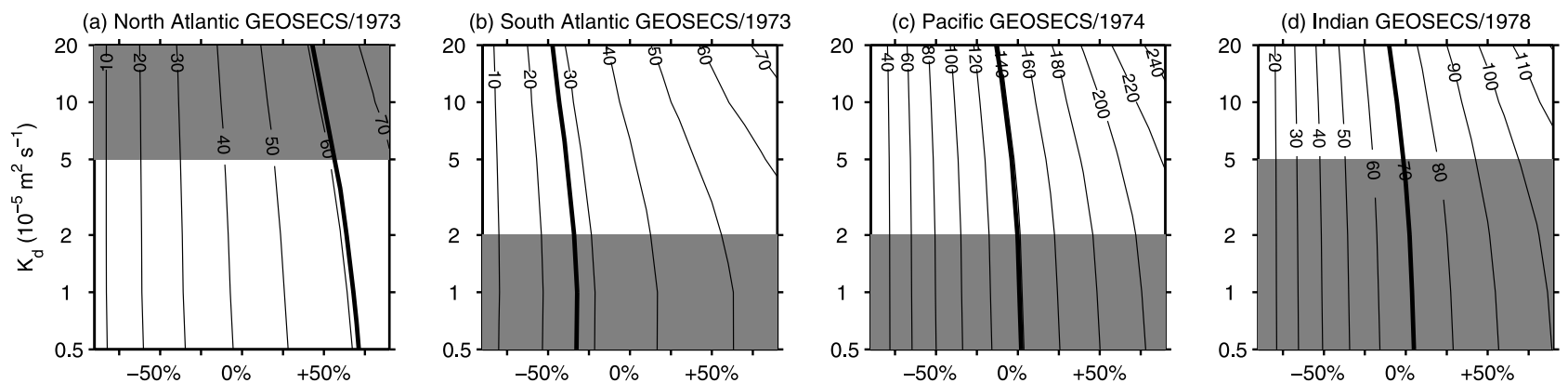

(e) North Atlantic TTO/1982
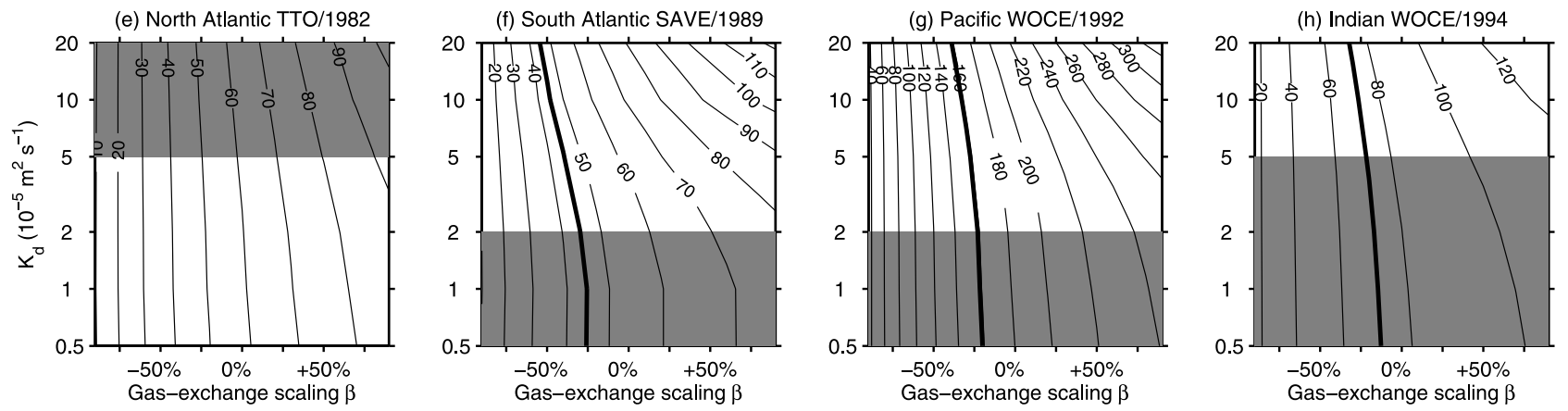

Figure 4. Simulated inventories of excess ${ }^{14} \mathrm{C}\left(10^{26}\right.$ atoms $)$ modified not to include the contribution due to changes in DIC for the GEOSECS era in (a) the North Atlantic for January 1973, (b) South Atlantic for January 1973, (c) Pacific for January 1974, and (d) Indian Ocean for January 1978, and for the TTO, SAVE, and WOCE era in (e) the North Atlantic, (f) South Atlantic, (g) Pacific, and (h) Indian Ocean. Shaded areas indicate the parameter range consistent with observation-based CFC-11 uptake estimates within error ranges. The bold line corresponds to the data-based inventory estimates of Broecker et al. [1995], Peacock [2004], and the integration from the GLODAP data set [Key et al., 2004].

integrated from the GLODAP data set [Key et al., 2004] for the North and South Atlantic for 1995 (1994 for the Pacific) are compared to the Bern3D model results to gauge the range of diapycnal diffusivity and thus transport strength for the respective basin. Generally, the data-based estimates are reproduced well within the simulated range. In all basins except the North Atlantic, the data-based CFC-inventory is reproduced by the model for low values of $K_{d}$, comparable to the default value of $1 \times 10^{-5} \mathrm{~m}^{2} \mathrm{~s}^{-1}$. The underestimation of CFC-11 in the Atlantic for standard parameter settings reflects the too weak MOC in the standard Bern3D setup [Müller et al., 2006], and $K_{d}$ has to be increased to (a) Ocean uptake 1965-1989

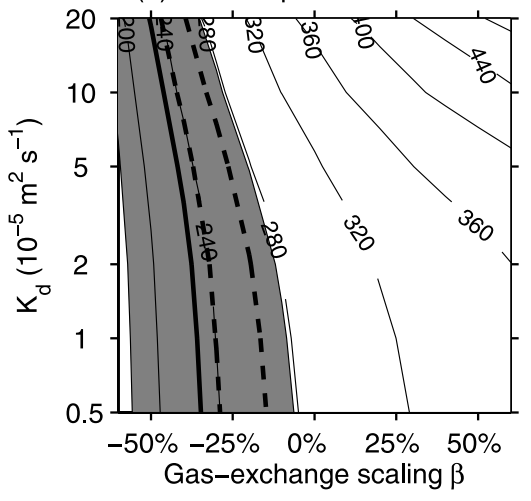

(b) Model - Data RMS difference

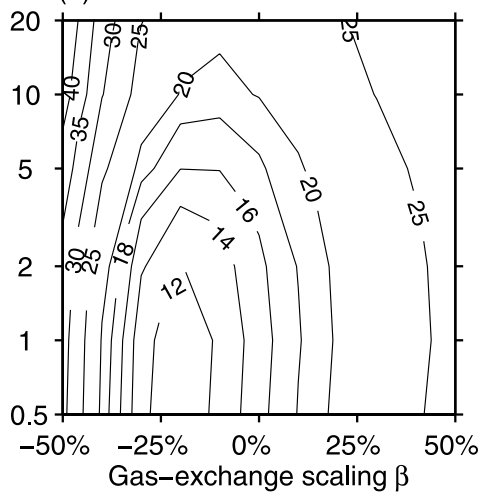

Figure 5. (a) The simulated change in oceanic inventory between July 1965 and July 1989 in $10^{26}$ atoms is compared to the estimates from the Earth system budget calculation of Joos [1994] (solid bold) and those based on the results of Naegler and Levin [2006] (dashed). The shaded region depicts the error range from Joos [1994]. (b) The global root mean square differences (\%o) between simulated preperturbation (annual mean of the year 1953) surface ocean $\Delta{ }^{14} \mathrm{C}$ and the GLODAP natural $\Delta^{14} \mathrm{C}$ field [Key et al., 2004]. 
Table 1. Inventories of Excess ${ }^{14} \mathrm{C}$ Simulated Using the Standard Setup of the Bern $3 \mathrm{D}$ and the Bern2.5D Model and Data-Based Estimates for Different Cruises Separated for Various Basins (in $10^{26}$ atoms) ${ }^{\text {a }}$

\begin{tabular}{|c|c|c|c|c|c|c|}
\hline Cruise/Model Year & Bern3D & Bern2.5D & $\frac{\operatorname{Inv}\left(\operatorname{DIC}(t), \Delta^{14} \mathrm{C}(1954)\right)}{\operatorname{Inv}\left(\operatorname{DIC}(t), \Delta^{14} \mathrm{C}(t)\right)}$ & B95 & P04 & K04 \\
\hline \multicolumn{7}{|c|}{ Global } \\
\hline GEOSECS/1975 & 305.3 & 303.1 & $4.0 \%$ & 305 & 271 & \\
\hline WOCE/1994 & 419.0 & 437.5 & $7.4 \%$ & & 353 & \\
\hline -/mid-1965 to mid-1989 & 290.5 & 314.6 & & & & \\
\hline \multicolumn{7}{|c|}{ North Atlantic } \\
\hline GEOSECS/1973 & 44.6 & 42.9 & $5.2 \%$ & 82.2 & 60.9 & \\
\hline$>70^{\circ} \mathrm{N}$ & 3.6 & 6.6 & $4.0 \%$ & 19.2 & 8.3 & \\
\hline TTO/1982 & 62.9 & 62.2 & $6.3 \%$ & 104.6 & & (39) \\
\hline$>70^{\circ} \mathrm{N}$ & 5.0 & 10.9 & $5.0 \%$ & 26.7 & & \\
\hline \multicolumn{7}{|c|}{ South Atlantic } \\
\hline GEOSECS/1973 & 37.4 & 41.6 & $4.2 \%$ & 29.2 & 26.72 & \\
\hline SAVE/1989 & 57.6 & 70.8 & $6.5 \%$ & 44.9 & & (44) \\
\hline \multicolumn{7}{|c|}{ Indian } \\
\hline GEOSECS/1978 & 70.9 & 70.1 & $3.8 \%$ & 73.5 & 69.95 & \\
\hline WOCE/1994 & 84.4 & 88.6 & $7.0 \%$ & & & 72 \\
\hline \multicolumn{7}{|c|}{ Pacific } \\
\hline GEOSECS/1974 & 142.5 & 139.5 & $3.5 \%$ & 144.5 & 138.35 & \\
\hline WOCE/1992 & 195.4 & 194.0 & $6.6 \%$ & & 158.7 & 164 \\
\hline
\end{tabular}

${ }^{\mathrm{a}}$ The fourth column reports the fraction of the simulated inventories due to the change in DIC concentrations derived from a simulation with the Bern3D model. The data-based estimates are from Broecker et al. [1995] (B95), from Peacock [2004] (P04), and calculated from the gridded GLODAP radiocarbon and DIC fields [Key et al., 2004] (K04). P04 data reported here are the mean values of the estimates resulting from the CFC-11 and CO based $^{2}$ methods of Peacock [2004], the GEOSECS global estimate has been adjusted for the year 1975. The integrations of the GLODAP data were performed using the gridded data set restricted by the domain where data are defined. The integrations for the Atlantic are reported at the times of the TTO and SAVE cruises.

match the data-based inventory. The diffusivity ranges assumed to be best compatible with the data-based CFCinventories are indicated by the dark gray shadings in Figure 4. These restricted ranges will be used for further quantitative analyses of the air-sea gas transfer velocity.

[32] The amount of excess ${ }^{14} \mathrm{C}$ for the North and South Atlantic, the Pacific and the Indian Ocean, for the approximate dates of the GEOSECS cruises in those basins, reduced by the fraction due to changing DIC concentrations, is compared with the data-based estimates in Figure 4. The weak influence of oceanic transport and near-linear response of the inventories to the gas exchange rate for the 1970s is evidenced by the almost vertical alignment of the isolines in this figure. At the time of the TTO, SAVE and WOCE campaigns in the $1980 \mathrm{~s}$ and $1990 \mathrm{~s}$, modeled basin-averaged inventories of excess ${ }^{14} \mathrm{C}$ (Figures $4 \mathrm{e}$ to $4 \mathrm{~h}$ ) are still strongly controlled by the gas transfer velocity, although ocean transport processes exert a slightly stronger control than for the GEOSECS inventories. Similarly, the change in the global ocean inventory over the period July 1965 to July 1989 depends only weakly on ocean transport (Figure 5a).

[33] The modeled pre-perturbation $\Delta^{14} \mathrm{C}$ surface ocean signature of the Bern3D model (Figure 5b) is also considered here. The minimum root mean square (RMS) differences increase from about $11 \%$ or fow $K_{d}$ to over $20 \%$ or high diapycnal diffusivity. Although the RMS difference is substantially affected by oceanic transport and the magnitude of $K_{d}$, these minima in RMS differences are found over a rather narrow range of the gas transfer scaling parameter $\beta$ (0.7 to 0.9$)$. Best agreement (RMS difference $<11 \%$ ) between the model and the GLODAP data set is found for a significantly downscaled OCMIP-2 gas transfer velocity field (by $18.0 \%$ to $21.6 \%)$ and for the default value of $K_{d}(1 \times$ $\left.10^{-5} \mathrm{~m}^{2} \mathrm{~s}^{-1}\right)$.

[34] The sensitivity simulations are used to estimate by how much the OCMIP-2 air-sea gas transfer velocity field must be scaled to match the different radiocarbon metrics. Table 2 summarizes the results for the Bern2.5D and the Bern3D models. The two models yield consistent results. The GEOSECS era inventory estimates for the Pacific and Indian oceans of Peacock [2004] approximately agree with the standard gas exchange field of the OCMIP-2. For all other metrics, except the North Atlantic inventories, the OCMIP-2 gas transfer velocity field must be scaled downward. On average, the OCMIP-2 field must be scaled down by $37 \%$ and $10 \%$ to match the excess ${ }^{14} \mathrm{C}$ inventory estimates of Peacock [2004] for the GEOSECS era for the South Atlantic and global ocean, respectively. To match the SAVE South Atlantic and the WOCE Pacific and Indian Ocean inventory estimates as well as the ocean uptake between 1965 and 1989, the necessary reductions of the gas transfer velocity range from $12 \%$ to $44 \%$.

\section{Optimal Estimate of the Air-Sea Gas Transfer Velocity From Intermediate Complexity Ocean Models and Revised Inventories of Excess ${ }^{14} \mathrm{C}$}

[35] We compute a weighted average of the estimated scaling factors for the Pacific and Indian Ocean inventories (GEOSECS and WOCE), the South Atlantic inventory 
Table 2. The Scaling Factors Required to Match ObservationBased Metrics (in Percent Deviation From Unity) ${ }^{\mathrm{a}}$

\begin{tabular}{lcc}
\hline Cruise/Model Year & $\beta_{\text {Bern3D }}$ & $\beta_{\text {Bern2.5D }}$ \\
\hline & Global & $-9.4 \%$ \\
GEOSECS/1975 & $-10.4 \%$ & $-20.8 \%$ \\
WOCE/1994 & $-30.1 \%(1 \times)$ & $-37.0 \%(1 \times)$ \\
$-/$ mid-1965 to mid-1989 & $-21.6 \%--18.0 \%(0.5 \times)$ \\
Pre-perturbation $\Delta^{14} \mathrm{C}$ & North Atlantic \\
(RMS diff. $<11 \% 0)$ & $43.0 \%-56.5 \%$ & $72.3 \%$ \\
\multicolumn{3}{c}{$>95.1 \%$} \\
GEOSECS/1973 & South Atlantic \\
TTO/1982 & $-34.1 \%--32.6 \%(0.5 \times)$ & $-40.4 \%(0.5 \times)$ \\
\multicolumn{3}{c}{ Indian } \\
GEOSECS/1973 & $-1.5 \%-5.0 \%(0.5 \times)$ & $5.3 \%(0.5 \times)$ \\
SAVE/1989 & $-21.3 \%--12.2 \%(0.5 \times)$ & $-19.8 \%(0.5 \times)$ \\
& & \\
GEOSECS/1978 & Pacific & \\
WOCE/1994 & $-0.2 \%-2.0 \%(1 \times)$ & $4.1 \%(1 \times)$ \\
& $-23.0 \%--20.1 \%(1 \times)$ & $20.7 \%(1 \times)$
\end{tabular}

$\underline{\text { Best guess scaling ( } \pm \text { std. dev.) }}$

$-19.3 \%( \pm 15.7 \%)$

${ }^{a}$ The averages from both models (the midpoint of the Bern3D ranges) have been used to determine an optimal scaling factor using the weights given in parentheses. The observation-based metrics are the data-based basin inventories reported in Table 1, the inferred change in global ocean inventory between mid-1965 and mid-1989, and the reconstructed $\Delta^{14} \mathrm{C}$ field. Data sources are Peacock [2004], Broecker et al. [1995], and Key et al. [2004], an average of the estimates of Joos [1994] and an estimate based on Naegler and Levin [2006] for the oceanic change between 1965 and 1989. The Bern3D model ranges are from simulations where the range of the diapycnal diffusivity is varied within the range determined from the CFC-11 inventory and as shown in gray in Figure 4 (the standard value of $K_{d}$ was used for global inventories). All scalings were linearly interpolated between results from simulations where scaling factors varied in steps of $10 \%$.

(GEOSECS and SAVE), the pre-perturbation $\Delta^{14} \mathrm{C}$ surface ocean RMS deviations from the GLODAP data, and for the global budget of bomb-produced radiocarbon for the period from 1965 to 1989 (Table 2). This yields a scaling factor, to be applied to the OCMIP-2 gas transfer velocity field, of 0.81 . Standard deviation of the mean scaling factors is 0.16 .

[36] The weights are selected as follows. An equal weight of one is given to each scaling factor except that a weight of two is assigned to those for the Pacific inventories and the Earth system budget. Uncertainties for all data-based metrics are of similar magnitude. A larger weight is given to the Pacific scaling factors as the Pacific is by far the largest basin, and uncertainties owing to transport processes of the simulated inventories are estimated to roughly scale with the inverse size of the basin. The relative constancy of the Earth system budget over the period 1965 to 1989 provides a reasonably strong constraint and is estimated to be only weakly influenced by transport uncertainties, while the surface ocean natural $\Delta^{14} \mathrm{C}$ field is more likely to be influenced by such uncertainties. The North Atlantic estimates are not included in the optimization as we are not able to reasonably reconcile the observation-based column inventory for the North Atlantic with the simulated column inventories of the other basins.
[37] Inventories modeled with the downscaled transfer velocity fields agree with the observation-based inventories given their large uncertainties for the global ocean and all basins, except the North Atlantic (Panels b and c of Figure 3 and Table 3). Because of the inclusion of the effect of the increase in DIC in the ocean, modeled inventories of excess ${ }^{14} \mathrm{C}$ are expected to be systematically larger than most of the data-based estimates. Further, it is not easy to quantify other uncertainties of the inventory estimates for excess ${ }^{14} \mathrm{C}$. Broecker et al. [1995] and Peacock [2004] assign an uncertainty of the order of $10 \%$ to their global estimates. These inventories have been obtained as the sum of individual basin-wide inventories corrected downward by $8 \%$ to take into account a potential bias arising from regions with shallow depths. Individual basin estimates have not been corrected for shallow waters by Broecker et al. [1995] and Peacock [2004], which could potentially contribute to a systematic overestimation of the data-based inventory estimates for the GEOSECS era used here. Other sources of uncertainties are sparse sampling, especially for the GEOSECS cruises, and uncertainties in separating background and excess radiocarbon from measurements. In Figure 3, an uncertainty bar of $15 \%$ is assumed, given that an uncertainty of the order of $10 \%$ is attributed to the sum of the basinwide inventories, and used for illustration, while the actual uncertainties may be different. Deviations between the modeled and the observation-based estimates are small for the South Atlantic and the WOCE era estimates for the Pacific and Indian Oceans. The model results with the downscaled field underestimates the GEOSECS Indian Ocean and Pacific inventory estimates strongest by about $13 \%$. Deviations between modeled and observationally inferred changes in global oceanic excess ${ }^{14} \mathrm{C}$ for the period from mid-1965 to mid-1989 are also within the uncertainties of the observation-based estimates for the Bern3D model (and slightly higher in the Bern2.5D simulation) and are small between the modeled and reconstructed surface $\Delta^{14} \mathrm{C}$ fields (Figure 5).

[38] Further, the modeled basin-mean specific inventory for the Atlantic, Indian, and Pacific vary within a restricted, small range upon modification of the spatial gas exchange pattern (Figure 3). In a simulation with the gas exchange scaling parameter $\beta$ set to 0.81 , basin mean specific inventories are within 0.59 and $0.83 \times 10^{14}$ atoms $\mathrm{m}^{-2}$ at the time of GEOSECS in the North and South Atlantic (sampled 1972/1973), the Pacific Ocean (1974/1975), and in the Indian (1978) and between 0.90 and $1.14 \times 10^{14}$ atoms $\mathrm{m}^{-2}$ for the North Atlantic at the time of TTO (simulated until 1982), the South Atlantic (SAVE, simulated until 1989), the Pacific (WOCE, simulated until 1992) and the Indian Ocean (WOCE, simulated until 1994) (Figure 3). This suggests that the applied model formulations result in similar basin-mean column inventories for all basins considered at a specific model year, and that they hardly depend on the examined spatial pattern of the gas exchange velocity field. The simulated column inventories agree well with, or are slightly below, the data-based estimates, except for the North Atlantic.

[39] Inventories for the 1990s and hindcast (Table 3) for comparison with the emerging data from the WOCE era. 
Table 3. Inventory Estimates of Excess ${ }^{14} \mathrm{C}$ (in $10^{26}$ Atoms) Simulated With the Bern3D and Bern2.5D Models Using the Gas Exchange Velocity Field From the OCMIP-2 Scaled Down by $(19.3 \pm 15.7) \%^{\mathrm{a}}$

\begin{tabular}{|c|c|c|c|}
\hline Cruise/Model Year & Bern3D & Bern2.5D & Data-Based Estimate \\
\hline \multicolumn{4}{|c|}{ Global } \\
\hline GEOSECS/1975 & $261(221-297)$ & $262(222-298)$ & 233 (H94)/305 (B95)/271 (P04) \\
\hline WOCE/1994 & $372(326-411)$ & $400(351-442)$ & $353(\mathrm{P} 04) / 343(\mathrm{~S} 07)$ \\
\hline -/mid-1965 to mid-1989 & $260(230-285)$ & $283(248-312)$ & $228 \pm 50(\mathrm{~J} 94) / 240,265(\mathrm{~N} 07)$ \\
\hline \multicolumn{4}{|c|}{ North Atlantic } \\
\hline GEOSECS/1973 & $40(33-46)$ & $37(30-42)$ & 60.9 (P04) \\
\hline TTO/1982 & $57(49-65)$ & $54(46-61)$ & 104.6 (B95) \\
\hline WOCE/1995 & $73(63-83)$ & $59(51-67)$ & \\
\hline \multicolumn{4}{|c|}{ South Atlantic } \\
\hline GEOSECS/1973 & $32(27-37)$ & $36(30-41)$ & 26.7 (P04) \\
\hline SAVE/1989 & $52(45-58)$ & $63(54-70)$ & 44.9 (B95) \\
\hline WOCE/1995 & $54(47-60)$ & $67(59-75)$ & \\
\hline \multicolumn{4}{|c|}{ Indian } \\
\hline GEOSECS/1978 & $62(52-70)$ & $61(52-69)$ & $70.0(\mathrm{P} 04)$ \\
\hline WOCE/1994 & $76(67-85)$ & $79(68-88)$ & 72.2 (integration based on GLODAP) \\
\hline \multicolumn{4}{|c|}{ Pacific } \\
\hline GEOSECS/1974 & $122(103-139)$ & $121(102-137)$ & 138.4 (P04) \\
\hline WOCE/1992 & $173(151-191)$ & $174(152-192)$ & 158.7 (P04) \\
\hline
\end{tabular}

${ }^{a}$ The model-derived inventory estimates are reported for a reduction of $19.3 \%$ of the gas exchange velocity field, the ranges given in parentheses correspond to reductions from 35.0\% to 3.6\%. Data sources are Hesshaimer et al. [1994] (H94) and Joos [1994] (J94), based on the results of Naegler and Levin [2006] (N07), Broecker et al. [1995] (B95), Peacock [2004] (P04), Key et al. [2004] (GLODAP), and Sweeney et al. [2007] (S07). The global values for the GEOSECS era of P04 and H94 have been adjusted with a factor 305/295 (the ratio of the global inventory estimates by Broecker et al. [1995] for January 1975 and January 1974, respectively).

Radiocarbon data from the Atlantic cruises (mid-1990s) have not yet been published. The two models suggest that the global inventory of excess ${ }^{14} \mathrm{C}$ is in the range of 372 to $400 \times 10^{26}$ atoms for 1994 , slightly higher than the estimate of Peacock [2004] based an the upscaled Pacific inventory estimate for the WOCE era in the mid-1990s and the estimate of Sweeney et al. [2007].

\section{Excess ${ }^{14} \mathrm{C}$ in the North Atlantic}

[40] The downscaled gas transfer velocity implies a substantially lower inventory of excess ${ }^{14} \mathrm{C}$ in the North Atlantic than the estimates of Broecker et al. [1995] (by a factor of about 1.6-2.3 at the time of TTO) and Peacock [2004] (by a factor of around 1.3-2.0). The Bern3D and Bern2.5D simulations suggest that the North Atlantic inventory is in the range of $(37-40) \times 10^{26}$ atoms for the GEOSECS era (1973), of 54 to $57 \times 10^{26}$ atoms at the time of TTO (1982), and of 59 to $73 \times 10^{26}$ atoms for the WOCE era (1995) (Table 3), if a reduction of $19 \%$ is applied to the standard gas transfer velocity. These modeled inventories were calculated by taking into account changes in the DIC concentration. What explains this discrepancy in the North Atlantic inventory of excess ${ }^{14} \mathrm{C}$ ?

[41] The Bern3D model settings used to simulate the excess ${ }^{14} \mathrm{C}$ inventories reproduce observation-based inventories of CFC-11 and anthropogenic carbon in the North Atlantic. The Bern3D model simulates an uptake of $25-$ 33 Gt of anthropogenic carbon in the North Atlantic (for January 1994) in good agreement with the data-based estimate of $28.4 \mathrm{GtC}$ of Lee et al. [2003] for the period 1990-1998. The data-based estimate for CFC-11 stored in the North Atlantic $\left(11 \times 10^{8}\right.$ moles integrated from the gridded GLODAP data set [Key et al., 2004] is reproduced well ( 9 to $12 \times 10^{8}$ moles of CFC-11 for the beginning of 1994 and south of $70^{\circ} \mathrm{N}$ ). The given ranges for the simulated inventories arise from varying transport strength $\left(K_{d}\right)$ and to a small degree from varying air-sea transfer rates $(\beta)$. In conclusion, the good agreement between simulated and data-based inventories of CFC-11 and anthropogenic carbon and the small uncertainties from lateral transport of excess ${ }^{14} \mathrm{C}$ discussed in section 5 imply that ocean model transport deficiencies cannot explain the discrepancy in the North Atlantic inventory of excess ${ }^{14} \mathrm{C}$. As noted previously, differences in the explored relationships between gas transfer and wind speed cannot account for the mismatch.

[42] Data sampling in the Arctic ocean is sparse. In the data-based estimates of Broecker et al. [1995] the latitudes north of $70^{\circ} \mathrm{N}$ contribute about $25 \%$ to the total North Atlantic/Arctic inventory of excess ${ }^{14} \mathrm{C}$ both for the TTO and GEOSECS data (Table 1). In contrast, Peacock [2004] reduces this contribution to about $14 \%$ for the GEOSECS inventories (Table 1), closer to that found in the two models. In any case, the contribution of the Arctic ocean to the total North Atlantic inventory is smaller than $25 \%$. Uncertainties in the Arctic inventory may imply an uncertainty of about $10 \%$ for the North Atlantic inventory of excess ${ }^{14} \mathrm{C}$. We conclude that uncertainties in the Arctic inventory cannot explain the discrepancy between the North Atlantic inventory and our model results.

[43] We next address the consistency between the reconstructed inventory for the North Atlantic and those of other ocean basins by comparing basin-mean column inventories (Figure 3). In contrast to expectations, reconstructed basin- 
mean column inventories in the North Atlantic [Broecker et al., 1995; Peacock, 2004] are much higher than in any other basin. A particular striking example is that the reconstructed North Atlantic inventory from the TTO data is about twice as large as the reconstructed Pacific column inventory from the WOCE data. This would imply that the integrated airsea flux of excess ${ }^{14} \mathrm{C}$ per unit area in the Pacific is much smaller even though the WOCE data were sampled about a decade after TTO. This points to a potential problem with the available data-based estimates of excess ${ }^{14} \mathrm{C}$ in the North Atlantic based on Broecker et al. [1995]. We recall that the column inventories estimated by Broecker et al. [1995] were substantially larger than those of Rubin and Key [2002] for the available GEOSECS stations in the midlatitudes of the North Atlantic, while differences in other basins are generally small. Apparently, reconstructed inventories are particularly sensitive to the choice of method used to separate natural and excess radiocarbon in parts of the North Atlantic. This might be related to the much deeper penetration of the bomb ${ }^{14} \mathrm{C}$ signal in the North Atlantic than in other areas. In conclusion, the data-based column inventories based on Broecker et al. [1995] for the North Atlantic are incompatible with those of other basins if the currently used parameterizations of air-sea gas transfer are valid.

\section{Summary and Conclusions}

[44] The pre-perturbation surface ocean distribution of $\Delta^{14} \mathrm{C}$, as well as the uptake and storage of excess ${ }^{14} \mathrm{C}$, CFC-11, and anthropogenic $\mathrm{CO}_{2}$ have been investigated by systematically varying transport parameters and air-sea gas transfer velocities in simulations performed with the Bern2.5D and Bern3D models. It was illustrated that the applied gas exchange velocity is an important parameter that strongly controls the basin-averaged inventories of excess ${ }^{14} \mathrm{C}$, whereas other factors, such as commonly used gas exchange-wind speed relationships and oceanic transport are of minor importance for the excess ${ }^{14} \mathrm{C}$ constraints considered here. Model results suggest that the influence of the cycling of biologically produced carbon and carbonate and the effect of global warming on excess ${ }^{14} \mathrm{C}$ uptake are negligible.

[45] Our analysis of the oceanic uptake of excess ${ }^{14} \mathrm{C}$ revealed inconsistencies between simulated and observation-based basin-wide inventories. We found that the inventories in the South Atlantic, Pacific and Indian Ocean, the pre-bomb global surface ocean $\Delta^{14} \mathrm{C}$ as well as the global Earth system budget for excess ${ }^{14} \mathrm{C}$ could be represented by the models within the uncertainty of the observation-based estimates, if the air-sea gas transfer velocity field from the OCMIP-2 is scaled down by $(19 \pm 16) \%$ (Table 2$)$. The best estimate for the mean air-sea gas transfer rate (averaged over the total Bern3D model's ocean surface including parts covered by sea ice) for a Schmidt number of 660 is then $17.1 \pm 3.3 \mathrm{~cm} \mathrm{~h}^{-1}$, in agreement with recent estimates of Naegler et al. [2006] and Sweeney et al. [2007], but lower than the estimates of Broecker et al. [1985], Wanninkhof [1992], and Krakauer et al. [2006].

[46] The gas transfer velocity reduced by $19 \%$ yields a global ocean inventory of excess ${ }^{14} \mathrm{C}$ of about $262 \times$
$10^{26}$ atoms for the GEOSECS era and of 372 to $400 \times$ $10^{26}$ atoms for the WOCE era (Table 3 ). We also suggest a North Atlantic inventory in the range of 37 to $40 \times 10^{26}$ atoms for the time of GEOSECS and in the range of 54 to $57 \times 10^{26}$ atoms for TTO, much smaller than previous estimates [Broecker et al., 1995; Peacock, 2004]; our estimate for the WOCE era lies in the range of 59 to $73 \times$ $10^{26}$ atoms (Table 3). The simulated global uptake of anthropogenic carbon in the 1980s and 1990s in the Bern3D model is consistent with other estimates [e.g., Plattner et al., 2002; Matsumoto et al., 2004; Manning and Keeling, 2006] and is only weakly affected by the downscaling of the applied gas exchange fields. The decadal-averaged uptake of the Bern3D model is, for the mean gas-exchange rate downscaled to $(81 \pm 16) \%$ of its original value, 1.70 to $1.79 \mathrm{GtC} \mathrm{a}^{-1}$ for the $1980 \mathrm{~s}$ and 1.94 to $2.02 \mathrm{GtC} \mathrm{a}^{-1}$ for the 1990s.

[47] We find a large difference between the data-based mean column inventory of excess ${ }^{14} \mathrm{C}$ in the North Atlantic and data-based mean column inventories in other basins (Figure 3). The current widely accepted parameterizations of air-sea transfer and the common understanding that airsea transfer is the rate limiting step for the uptake of excess ${ }^{14} \mathrm{C}$ implies that basin-averaged column inventories should be roughly equal among different basins and for the same time period. This expectation is quantitatively confirmed by our model analysis.

[48] We have examined potential reasons for the discrepancy. The influence of a modified spatial pattern of the air-sea gas transfer velocity, or massively altered ocean transport and surface-to-deep mixing strength on basinwide inventories of excess ${ }^{14} \mathrm{C}$ is weak, and, unlikely to explain the difference. Additional mechanisms, which are presently not explicitly included in the gas exchange formulations, such as chemical enhancement by surface films [Wanninkhof, 1992; Boutin et al., 1999], wave regimes, and bubble entrainment, may potentially lead to stronger air-sea gas transfer in the North Atlantic than in other basins. However, there is currently no evidence that the situation in the North Atlantic is very distinct from elsewhere. We emphasize that we do not question the ${ }^{14} \mathrm{C}$ measurements themselves that represent the sum of natural and excess radiocarbon. A comparison between different published reconstructions of excess radiocarbon reveals large uncertainties in the determination of the column inventories in the mid-latitudes of the North Atlantic [Broecker et al., 1995; Rubin and Key, 2002] related to the method applied to separate excess from natural radiocarbon. Differences in results from different methods are relatively small in other basins. Our analysis tends to favor separation methods that yield lower inventories of excess ${ }^{14} \mathrm{C}$ than the approach of Broecker et al. [1995]. In summary, we conclude that current parameterizations of air-sea gas transfer and the observation-based estimate of the basin-wide inventory of excess ${ }^{14} \mathrm{C}$ in the North Atlantic are not compatible. We further suggest that the data-based inventory estimates by Broecker et al. [1995] and Peacock [2004] are likely too high for the North Atlantic. The forthcoming ${ }^{14} \mathrm{C}$ data from the North Atlantic WOCE cruises will likely be instrumental to resolve the enigmatic discrepancy between available 
data-based basin-averaged column inventories for the North Atlantic and for other basins and to further improve our quantitative understanding of the air-sea gas transfer rate.

\section{Appendix A: Radiocarbon and Air-Sea Gas Exchange Formulation}

[49] $\Delta{ }^{14} \mathrm{C}$ is related to the fractionation-corrected ${ }^{14} \mathrm{C}$ to ${ }^{12} \mathrm{C}$ ratio, ${ }^{14} \mathrm{R}_{\mathrm{N}}$, using

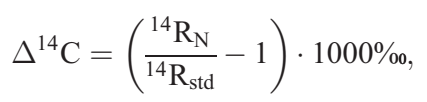

where ${ }^{14} \mathrm{R}_{\text {std }}=1.176 \times 10^{-12}$ [Siegenthaler, 1989]. The fractionation-corrected ratios in the atmosphere, ${ }^{14} \mathrm{R}_{\mathrm{N}, \mathrm{a}}$, and the ocean, ${ }^{14} \mathrm{R}_{\mathrm{N}, \mathrm{o}}$, are used to calculate the air-sea gas exchange. Total DIC (DIC $=\mathrm{DI}^{12} \mathrm{C}+\mathrm{DI}^{13} \mathrm{C}+\mathrm{DI}^{14} \mathrm{C}$ ) and the radiocarbon tracer DIC14 are transported independently. The two tracers DIC and DIC14 are related to $\mathrm{R}_{\mathrm{N}, \mathrm{o}}$ by

$$
{ }^{14} \mathrm{R}_{\mathrm{N}, \mathrm{o}}=\frac{\mathrm{DIC} 14}{\mathrm{DIC}} \cdot{ }^{14} \mathrm{R}_{\mathrm{std}} .
$$

[50] To compute the actual fractionation-normalized $\mathrm{DI}^{14} \mathrm{C}_{\mathrm{N}}$ concentration, the ratio of $\mathrm{DI}^{12} \mathrm{C}$ to total DIC is approximated and one obtains with the help of equation (A2)

$$
\mathrm{DI}^{14} \mathrm{C}_{\mathrm{N}}={ }^{14} \mathrm{R}_{\mathrm{N}, \mathrm{o}} \cdot \mathrm{DI}^{12} \mathrm{C} \approx \frac{\mathrm{DIC} 14 \cdot{ }^{14} \mathrm{R}_{\mathrm{std}}}{1+\left(\frac{\delta^{13} \mathrm{C}+1000 \%}{1000 \%}\right) \cdot{ }^{13} \mathrm{R}_{\mathrm{std}}},
$$

where ${ }^{13} \mathrm{R}_{\text {std }}=1.12372 \times 10^{-2}$ [Craig, 1957]. $\mathrm{DI}^{14} \mathrm{C}_{\mathrm{N}}$ is converted into radiocarbon concentrations ${ }^{14} \mathrm{C}$ according to

$$
{ }^{14} \mathrm{C}_{\mathrm{N}}=\mathrm{DI}^{14} \mathrm{C}_{\mathrm{N}} \frac{1000 \% 0}{1000 \% 0-2\left(\delta^{13} \mathrm{C}+25 \%\right)} \cdot N_{A},
$$

with the Avogadro Number $N_{A}=6.022045 \times 10^{23}$ atoms $\mathrm{mol}^{-1}$. Throughout this work $\delta^{13} \mathrm{C}$ is set to $0.8 \%$ (and to $-20 \%$ for dissolved organic carbon, DOC, which is used in the sensitivity study including the biological carbon cycle), a typical value for the upper ocean's $\delta^{13} \mathrm{C}$ signature where most of the excess ${ }^{14} \mathrm{C}$ is found. Excess ${ }^{14} \mathrm{C}$ (after 1954) is defined as the difference of the simulated radiocarbon inventory minus that simulated at the beginning of 1954 .

[51] The climatology for the air-sea gas transfer velocity $k_{1,2}$ for a Schmidt number of 660 from the OCMIP-2 was used to calculate different dependencies of the gas transfer velocity on wind speed, $u$, using the form $k_{1, n}=c_{n} \cdot u^{n}$, where $c_{n}$ is a coefficient and $n$ is varied between 0 and 3 . We approximate $k_{1, n}$ from $k_{1,2}$ similar to Krakauer et al. [2006] by using

$$
k_{1, n}(\vec{x}, t)=\frac{\overline{k_{1,2}(\vec{x}, t)}}{\left(k_{1,2}(\vec{x}, t)\right)^{\frac{n}{2}}}\left(k_{1,2}(\vec{x}, t)\right)^{\frac{n}{2}}
$$

[52] The bar denotes the spatial and annual average taken over the surface ocean. This procedure does not produce climatologies for the $u^{1}$ and $u^{3}$ relationships including higher moments. The square root of the OCMIP-2 gas exchange field (which incorporates the variance of the wind speed) has been used instead of actual wind speeds. Our estimate retains the $u^{2}$ relationship, while providing an interpolation between the spatially constant ( $u^{0}$ relationship) and the standard $\left(u^{2}\right)$ case and an extrapolation toward enhanced high wind speed regions and reduced low wind speed regions. Ice coverage has been ignored when computing the averages which introduces slight deviations of up to $4 \%$ on the mean gas exchange velocities over the ice-free parts of the ocean.

[53] Acknowledgments. This project was funded by the Swiss National Science Foundation, the Swiss Federal Office for the Environment, and the EU projects CARBOOCEAN (511176-2), and EUROCEANS (511106-2). The authors would like to thank T. Naegler for useful discussions.

\section{References}

Boutin, J., J. Etcheto, and P. Ciais (1999), Possible consequences of the chemical enhancement effect for air-sea $\mathrm{CO}_{2}$ flux estimates, Phys. Chem. Earth Part B, 24(5), 411-416.

Broecker, W. S., T. Peng, G. Ostlund, and M. Stuiver (1985), The distribution of bomb radiocarbon in the ocean, J. Geophys. Res., 90(C4), 69536970 .

Broecker, W. S., J. R. Ledwell, T. Takahashi, R. Weiss, L. Merlivat, L. Memery, T. Peng, B. Jahne, and K. O. Munnich (1986), Isotopic versus micrometeorologic ocean $\mathrm{CO}_{2}$ fluxes: A serious conflict, J. Geophys. Res., 91(C9), 10,517-10,527.

Broecker, W. S., S. Sutherland, W. Smethie, T. Peng, and G. Ostlund (1995), Oceanic radiocarbon: Separation of the natural and bomb components, Global Biogeochem. Cycles, 9(2), 263-288.

Craig, H. (1957), Isotopic standards for carbon and oxygen and correction factors for mass-spectrometric analysis of carbon dioxide, Geochim. Cosmochim. Acta, 12(1-2), 133-149.

Edwards, N. R., A. J. Willmott, and P. D. Killworth (1998), On the role of topography and wind stress on the stability of the thermohaline circulation, J. Phys. Oceanogr., 28(5), 756-778.

Ganachaud, A., and C. Wunsch (2000), Improved estimates of global ocean circulation, heat transport and mixing from hydrographic data, Nature, 408(6811), 453-457.

Heimann, M., and E. Maier-Reimer (1996), On the relations between the oceanic uptake of $\mathrm{CO}_{2}$ and its carbon isotopes, Global Biogeochem. Cycles, 10(1), 89-110.

Hesshaimer, V., M. Heimann, and I. Levin (1994), Radiocarbon evidence for a smaller carbon dioxide sink than previously believed, Nature, 370(6486), 201-203.

Ho, D. T., C. S. Law, M. J. Smith, P. Schlosser, M. Harvey, and P. Hill (2006), Measurements of air-sea gas exchange at high wind speeds in the southern ocean: Implications for global parameterizations, Geophys. Res. Lett., 33(16), L16611, doi:10.1029/2006GL026817.

Joos, F. (1994), Imbalance in the budget, Nature, 370(8486), 181-182.

Joos, F., and M. Bruno (1998), Long-term variability of the terrestrial and oceanic carbon sinks and the budgets of the carbon isotopes ${ }^{13} \mathrm{C}$ and ${ }^{14} \mathrm{C}$, Global Biogeochem. Cycles, 12(2), 277-295.

Kalnay, E., et al. (1996), The NCEP/NCAR 40-year reanalysis project, Bull. Am. Meteorol. Soc., 77(3), 437-471.

Key, R. M., et al. (2004), A global ocean carbon climatology: Results from global data analysis project GLODAP, Global Biogeochem. Cycles, 18(4), GB4031, doi:10.1029/2004GB002247.

Krakauer, N. Y., J. T. Randerson, F. W. Primeau, N. Gruber, and D. Menemenlis (2006), Carbon isotope evidence for the latitudinal distribution and wind speed dependence of the air-sea gas transfer velocity, Tellus, Ser. B, 58B(5), 390-417, doi:10.1111/j.1600-0889.2006.00223.x.

Lee, K., et al. (2003), An updated anthropogenic $\mathrm{CO}_{2}$ inventory in the Atlantic Ocean, Global Biogeochem. Cycles, 17(4), 1116, doi:10.1029/ 2003GB002067.

Liss, P. S., and L. Merlivat (1986), Air-sea gas exchange rates: Introduction and synthesis, in The Role of Air-Sea Exchange in Geochemical Cycling, edited by P. Buat-Ménard, pp. 113-127, D. Reidel, Hingham, Mass. 
Manning, A. C., and R. F. Keeling (2006), Global oceanic and land biotic carbon sinks from the Scripps atmospheric oxygen flask sampling network, Tellus, Ser. B, 58B(2), 95-116.

Marchal, O., T. F. Stocker, and F. Joos (1998), A latitude-depth, circulationbiogeochemical ocean model for paleoclimate studies. Development and sensitivities, Tellus, Ser. B, 50B(3), 290-316.

Matsumoto, K., et al. (2004), Evaluation of ocean carbon cycle models with data-based metrics, Geophys. Res. Lett., 31(7), L07303, doi:10.1029/ 2003GL018970.

Müller, S. A., F. Joos, N. R. Edwards, and T. F. Stocker (2006), Water mass distribution and ventilation time scales in a cost-efficient, threedimensional ocean model, J. Clim., 19(21), 5479-5499, doi:10.1175/ JCLI3911.1.

Muscheler, R., F. Joos, S. A. Müller, and I. Snowball (2005), How unusual is today's solar activity?, Nature, 436, E3-E4, doi:10.1038/ nature 04045 .

Naegler, T., and I. Levin (2006), Closing the global radiocarbon budget 1945-2005, J. Geophys. Res., 111(D12), D12311, doi:10.1029/ 2005JD006758

Naegler, T., P. Ciais, K. Rodgers, and I. Levin (2006), Excess radiocarbon constraints on air-sea gas exchange and the uptake of $\mathrm{CO}_{2}$ by the oceans, Geophys. Res. Lett., 33(11), L11802, doi:10.1029/2005GL025408.

Nightingale, P. D., G. Malin, C. S. Law, A. J. Watson, P. S. Liss, M. I Liddicoat, J. Boutin, and R. C. Upstill-Goddard (2000), In situ evaluation of air-sea gas exchange parameterizations using novel conservative and volatile tracers, Global Biogeochem. Cycles, 14(1), 373-387.

Orr, J. C. (1999), On ocean carbon-cycle model comparison, Tellus, Ser. B, $51 B(2), 509-510$

Peacock, S. (2004), Debate over the ocean bomb radiocarbon sink: Closing the gap, Global Biogeochem. Cycles, 18(2), GB2022, doi:10.1029/ 2003 GB002211.

Plattner, G.-K., F. Joos, T. F. Stocker, and O. Marchal (2001), Feedback mechanisms and sensitivities of ocean carbon uptake under global warming, Tellus, Ser. B, 53B(5), 564-592.

Plattner, G.-K., F. Joos, and T. F. Stocker (2002), Revision of the global carbon budget due to changing air-sea oxygen fluxes, Global Biogeochem. Cycles, 16(4), 1096, doi:10.1029/2001GB001746.

Ritz, S. P., T. F. Stocker, and S. A. Müller (2008), Modeling the effect of abrupt ocean circulation change on marine reservoir age, Earth Planet. Sci. Lett., 268(1-2), 202-211, doi:10.1016/j.epsl.2008.01.024.
Rubin, S. I., and R. M. Key (2002), Separating natural and bomb-produced radiocarbon in the ocean: The potential alkalinity method, Global Biogeochem. Cycles, 16(4), 1105, doi:10.1029/2001GB001432.

Siegenthaler, U. (1989), Carbon-14 in the oceans, in Handbook of Environmental Isotope Geochemistry, vol. 3, edited by P. Fritz and J. C. Fontes chap. 3, pp. 75-137, Elsevier, New York.

Stocker, T. F., D. G. Wright, and L. A. Mysak (1992), A zonally averaged, coupled ocean-atmosphere model for paleoclimate studies, J. Clim., 5(8), $773-797$.

Sweeney, C., E. Gloor, A. R. Jacobson, R. M. Key, G. McKinley, J. L. Sarmiento, and R. Wanninkhof (2007), Constraining global air-sea gas exchange for $\mathrm{CO}_{2}$ with recent bomb ${ }^{14} \mathrm{C}$ measurements, Global Biogeochem. Cycles, 21(2), GB2015, doi:10.1029/2006GB002784.

Takahashi, T., et al. (2002), Global sea-air $\mathrm{CO}_{2}$ flux based on climatological surface ocean $p \mathrm{CO}_{2}$, and seasonal biological and temperature effects, Deep Sea Res., Part II, 49(9-10), 1601-1622.

Talley, L. D., J. L. Reid, and P. E. Robbins (2003), Data-based meridional overturning streamfunctions for the global ocean, J. Clim., 16(19), $3213-3226$

Wanninkhof, R. (1992), Relationship between wind speed and gas exchange over the ocean, J. Geophys. Res., 97(C5), 7373-7382.

Wanninkhof, R., and W. R. McGillis (1999), A cubic relationship between air-sea $\mathrm{CO}_{2}$ exchange and wind speed, Geophys. Res. Lett., 26(13), $1889-1892$

Willey, D. A., R. A. Fine, R. E. Sonnerup, J. L. Bullister, W. M. Smethie Jr., and M. J. Warner (2004), Global oceanic chlorofluorocarbon inventory, Geophys. Res. Lett., 31(1), L01303, doi:10.1029/ 2003GL018816.

N. R. Edwards and S. A. Müller, Department of Earth and Environmental Sciences, The Open University, Milton Keynes MK7 6AA, UK. (n.r. edwards@open.ac.uk; s.a.mueller@open.ac.uk)

F. Joos and T. F. Stocker, Climate and Environmental Physics, Physics Institute, University of Bern, Sidlerstrasse 5, CH-3012 Bern, Switzerland. (joos@climate.unibe.ch; stocker@climate.unibe.ch)

G.-K. Plattner, Environmental Physics, Institute of Biogeochemistry and Pollutant Dynamics, ETH Zürich, CH-8092 Zürich, Switzerland. (gian-kasper.plattner@env.ethz.ch) 